
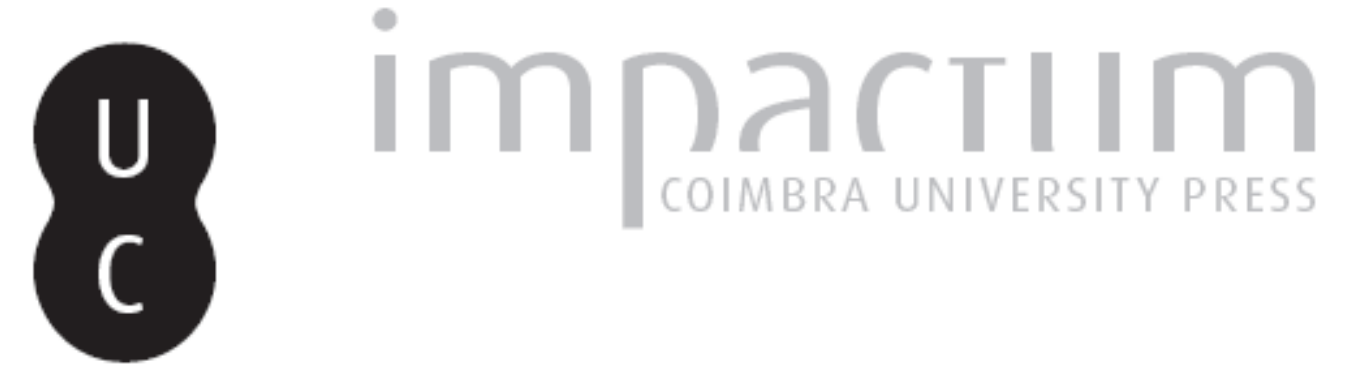

\title{
Biodiversidade e riscos antrópicos no Nordeste do Brasil
}

Autor(es): $\quad$ Castro, Antonio Alberto Jorge Farias

Publicado por: Associação Portuguesa de Riscos, Prevenção e Segurança

URL persistente:

URI:http://hdl.handle.net/10316.2/40071

DOI:

DOI:https://doi.org/10.14195/1647-7723_10_3

Accessed : $\quad$ 26-Apr-2023 02:01:31

A navegação consulta e descarregamento dos títulos inseridos nas Bibliotecas Digitais UC Digitalis, UC Pombalina e UC Impactum, pressupõem a aceitação plena e sem reservas dos Termos e Condições de Uso destas Bibliotecas Digitais, disponíveis em https://digitalis.uc.pt/pt-pt/termos.

Conforme exposto nos referidos Termos e Condições de Uso, o descarregamento de títulos de acesso restrito requer uma licença válida de autorização devendo o utilizador aceder ao(s) documento(s) a partir de um endereço de IP da instituição detentora da supramencionada licença.

Ao utilizador é apenas permitido o descarregamento para uso pessoal, pelo que o emprego do(s) título(s) descarregado(s) para outro fim, designadamente comercial, carece de autorização do respetivo autor ou editor da obra.

Na medida em que todas as obras da UC Digitalis se encontram protegidas pelo Código do Direito de Autor e Direitos Conexos e demais legislação aplicável, toda a cópia, parcial ou total, deste documento, nos casos em que é legalmente admitida, deverá conter ou fazer-se acompanhar por este aviso.

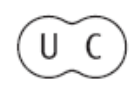




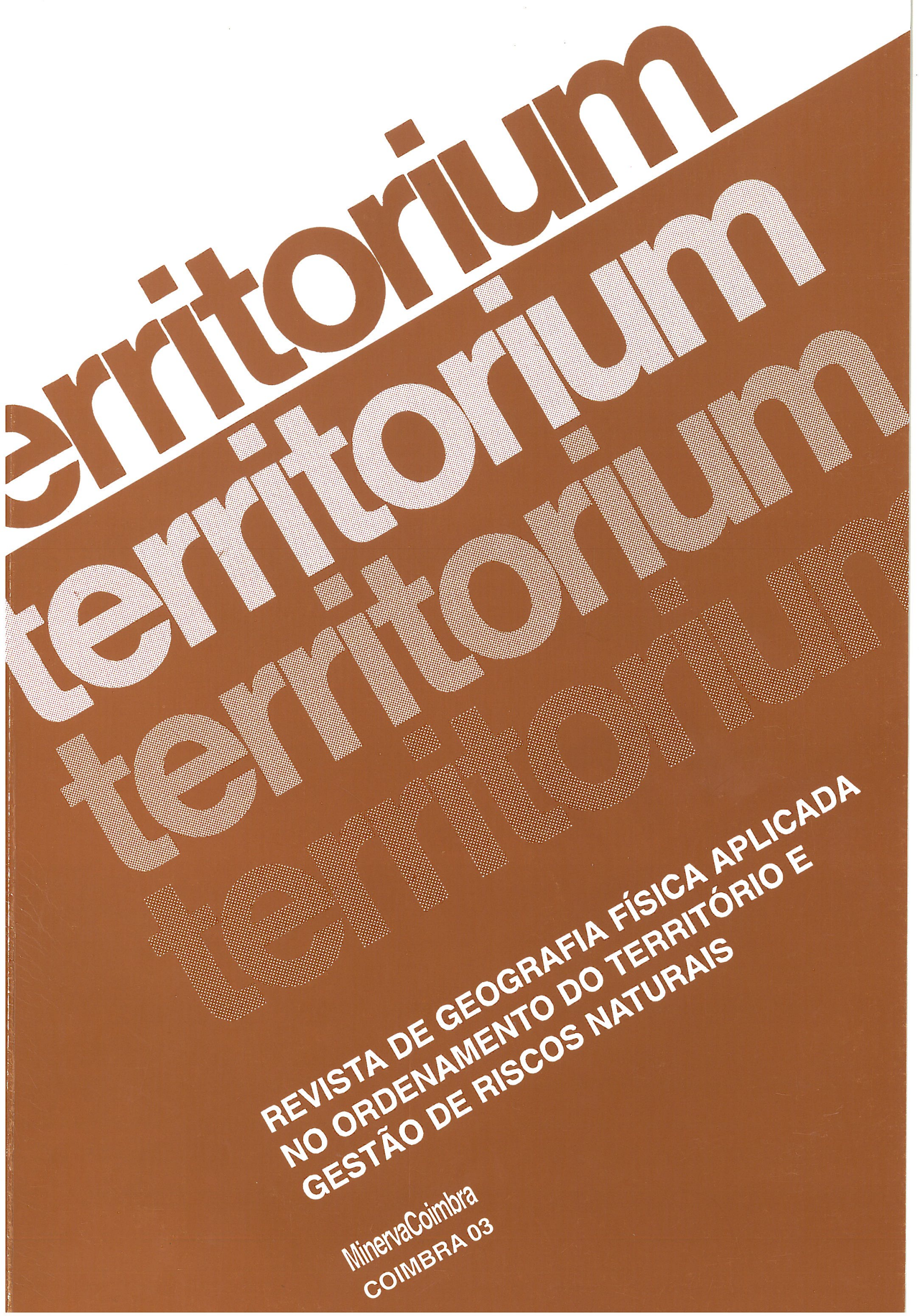




\title{
Biodiversidade e Riscos Antrópicos no Nordeste do Brasil ${ }^{*}$
}

\author{
Antonio Alberto Jorge Farias Castro**
}

\begin{abstract}
Resumo:
$\mathrm{O}$ artigo chama a atenção para a premissa de que a biodiversidade representa uma das mais importantes bases do desenvolvimento cultural, social e econômico da espécie humana e que suas perdas estão também associadas aos riscos naturais (seca) e antrópicos (desmatamento, fogo e desertificação) no Nordeste do Brasil.

Palavras-chave:

Biodiversidade, seca, desmatamento, fogo, desertificação, Nordeste do Brasil.

Résumé:

L'article introduit la prémisse que la biodiversité représente une des bases les plus importantes du développement culturel, social et économique de l'espèce humaine et que leurs pertes sont aussi associées aux risques naturels (secheresse) et anthropiques (déboisement, feu et désertification) dans le Nord-est dı Brésil.

Mots-clés:

Biodiversité, sécheresse, déboisement, feu, désertification, Nord-est de Brésil.
\end{abstract}

Abstract:

The article introduces the premise that biodiversity represents one of the most important bases of the cultural, social, and economical development of the human species and that its losses are also associated to the natural (drought) and anthropical risks (deforestation, fire and desertification) in the Northeast of Brazil.

Keys words:

Biodiversity, drought, deforestation, fire, desertification, Northeast of Brazil.

\section{Introdução}

A diversidade biológica deve considerar dois aspectos, um relacionado à idéia de heterogeneidade (variedade de espécies)e, outro, à idéia de equabilidade (proporção de abundância entre populações). Sua importância ainda não é grande porque o seu conhecimento ainda está em uma fase de perquirição. A degradação ambiental, a desertificação, o aquecimento

\footnotetext{
* Palestra proferida no dia 22/11/2002 durante o IX Encontro sobre Riscos Naturais, Universidade de Coimbra, Coimbra (PORTUGAL).

* Mestre em Botânica e Doutor em Ecologia Vegetal pela UNICAMP. Coordenador Geral do Núcleo de Referência em Ciências Ambientais do Trópico Ecotonal do Nordeste (TROPEN). Pró-Reitoria de Pesquisa e Pós-Graduação. Universidade Federal do Piauí (UFPI). Av. Universitária, 1310. Campus da Ininga. 64049 - 550 - Teresina - Piauí - Brasil. Fone:Fax: + $55(0++86)$ 215.5566. E-mail: aajicastro@uol.com.br.
}

global e as mudanças climáticas têm relação estreita com as perdas da biodiversidade.

No campo de estudo de desastres, a ruptura no funcionamento normal de uma comunidade, devido à ocorrência de eventos naturais (riscos naturais) ou não (riscos antrópicos), pode ser caracterizada também através das alterações ambientais que se acumulam. As perdas da biodiversidade são uma dessas alterações ambientais. $O$ fogo (incêndios florestais) e o corte de lenha (desmatamento) nos ecossistemas do Nordeste, por exemplo, continuam porque, de fato, poucas alternativas são conhecidas e exploradas e, porque, em condições de resistência de permanência no campo, homens e mulheres absorvem as opções que a eles são, no momento, oferecidas. Terminadas estas opções, porque os recursos não são renováveis da maneira como é utilizada, a exclusão social dos principais 
atores acontece, formando-se as rupturas das ligações culturais entre as gerações diretamente envolvidas. A promiscuidade em termos de nomeação popular de espécies vegetais reflete bemeste aspecto. Estabelece-se o êxodo rural com o conseqüente e lento esvaziamento do campo.

Diferentemente do que ocorre nobioma da Caatinga, o principal fator de pressão e impacto ambiental sobre o bioma do Cerrado está nos modelos de ocupação do espaço e produção adotados pelo "agribusiness", porque seus modelos têm relação estreita com os padrões de consumo e matrizes energéticas vigentes nos países superindustrializados, sem levar em plena consideração os impactos econômicos, sociais e ambientais decorrentes, sua população e o país como um todo. A ocupação dos Cerrados brasileiros, e agora, os do Nordeste, acontece muitos anos na frente do domínio do conhecimento científico a respeito deles. Desta maneira, o empobrecimento genético (erosão genética) ocorre de modo acentuado e abrupto, por ocasião dos desmatamentos em grande escala, principalmente porque estes não consideram as características do terreno, as particularidades do clima, as limitações geológicas e geomorfológicas, as ilhas de biodiversidade e os corredores de ligação (corredores ecológicos). Ao empobrecimento da diversidade biológica segue-se a fragilidade dos controles biológicos naturais, com a sua substituição pelos controles biológicos artificiais e pelos controles químicos, gerando desastres ecológicos com amplas repercussões econômicas e sociais de desagregação.

Os números de espécies vegetais e animais ameaçados de extinção já começam a assustar. No Nordeste brasileiro, em grande escala, a seca é o principal risco natural. Sendo cíclica, depende apenas de gerenciamento de tecnologias para a convivência com os seus efeitos. Como riscos antrópicos destacam-se os desmatamentos, as queimadas e a desertificação. No Semi-Árido nordestino os processos de desertificação se ampliam. Conceitos ainda se discutem. Um conceito de "desertificação sensu lato" resolveria o problema? Soluções como o aporte de recursos financeiros aparecem somente em relatórios. Parece que uma "indústria da desertificação" candidata-se a substituir a tão falada "indústria da seca". A questão das escalas de trabalho é importante, a participação das Universidades não pode ser desconsiderada.

O número de unidades de conservação (UCs) cresce no país, principalmente em termos de UCs de uso sustentável, colocando em conflito os ambientalistas e os sócio-ambientalistas. Entretanto, as UCs continuam com áreas muito pequenas, contribuindo pouco para a reversão das questões de fragmentação cada vez maior dos ecossistemas remanescentes. As Reservas Particulares do Patrimônio Natural (RPPNs) têm se ampliado, mas em geral suas áreas são muito pequenas.
São importantes porque demonstram a cumplicidade crescente da iniciativa privada com as questões ambientais. O Brasil e o Nordeste ainda estão longe de ter $10 \%$ de suas áreas protegidas em UCs, quando se acredita que $30 \%$ é que seriam os ideais (DOUROJEANNI \& PÁDUA, 2001). A elaboração de mapas temáticos com indicação de áreas prioritárias para a conservação da biodiversidade, por exemplo, promete orientar mudanças em termos de formulação de políticas públicas.

O mito da homogeneidade florística discutido para a Caatinga (ANDRADE-LIMA, 1981) e para Floresta Amazônica (TCA, 1992), é conhecido para os Cerrados brasileiros (CASTRO, 1994). No Piauí as Caatingas correspondemà primeira maior formação vegetacional do Estado. Os Cerrados estão em segundo lugar. Mais importante e, neste ponto o Piauí se destaca dos outros estados brasileiros, é com a presença de enormes áreas de tensão ecológica, as áreas transicionais ou áreas ecotonais nas quais ocorrem os contatos do Cerrado, da Caatinga e do Carrasco em espaços geográficos com relevo suavemente ondulado em quase toda a extensão do território piauiense. Neste aspecto, vale destacar o Complexo de Campo Maior, com suas extensas áreas de solos mal drenados, e as áreas que conectam o sudoeste e sudeste do Estado, com a presença de manchas de Cerrado caducifólio, de um lado, e de prováveis remanescentes de Mata Atlântica de interior, de outro. Se o conhecimento sobre o Cerradoe a Caatinga ainda é pouco, menos ainda o é para os ecótonos cerrado/caatinga comprometendo mais ainda a sua performance em termos de biologia da conservação, uma vez que não se conserva o que se desconhece. $O$ (re)conceito de nação, inclusive, permeia esta questão.

\section{A Biodiversidade: Conceito, Importância e Abordagens}

A biodiversidade diz respeito à variabilidade dos organismos vivos de todas as origens, compreendendo, entre outros, os ecossistemas terrestres e marinhos, outros ecossistemas aquáticos e os complexos ecológicos de que fazem parte, envolvendo ainda a diversidade dentro das espécies, entre espécies e de ecossistemas.

A importância da biodiversidade tem a ver com o fato de que todos os alimentos que comemos e grande parte das roupas e remédios que usamos são produtos diretos da diversidade biológica. Além do mais, ela estádiretamente relacionada ao funcionamento dos ecossistemas e presta importantes serviços ecológicos a todas as espécies, principalmente à espécie humana, como, por exemplo, o ciclo do carbono, o ciclo do oxigênio, o ciclo do nitrogênio (e outros 
ciclos biogeoquímicos) e a regulação do clima (ao nível do Planeta).

A destruição da biodiversidade leva à degradação ambiental (de solos, águas e atmosfera) è desertificação em regiões áridas, semi-áridas e subúmidas secas, ao aquecimento global (efeito estufa) e a mudanças climáticas ao nível de grande escala.

Várias são as abordagens que se pode fazer sobre a biodiversidade. Quando o conjunto da informação genética existente nas espécies que constituem a flora (vegetais), a fauna (animais) e a microbiota (microrganismos) é o foco, estamos falando de diversidade genética. Quando o número de espécies e suas relações de abundância (fitossociologia), relacionadas com os diferentes habitats (locais) ou ecossistemas existentes é o que interessa diretamente, falamos de diversidade de espécies. Quando o foco, enfim, é o número, frequiência, variedade de habitats (locais), comunidades bióticas e processos ecológicos, estamos nos referindo à diversidade de ecossistemas.

Por outro lado, quando os estudos são de taxonomia (classificação, determinação e identificação), flora (conjunto de espécies vegetais), florística (flora associada a estimativas de amostragem) e fitogeografia (qualitativa e quantitativa) de plantas, estamos nos referindo a uma biodiversidade de tipo. Por sua vez, quando os estudos são de morfologia externa (organografia) e anatomia (morfologia interna) e de desenvolvimento dos sistemas radiculares (radicilares), dos sistemas subterrâneos de plantas, e estudos de anatomia ecológica de folhas, ofocoé a biodiversidade de forma. Quando os estudos estão voltados para as estratégias fisiológicas adaptativas de espécies vegetais aos estresses do meio ambiente, passamos a falar, então, de biodiversidade de função.

\section{Os Desastres e a Biodiversidade: Implicações}

No escopo dos estudos de desastres, segundo THOMAS (1994a), a ruptura no funcionamento normal de uma comunidade, devido a ocorrência de eventos naturais ou não, pode ser caracterizada também através das alterações ambientais que se acumulam, na medida em que estas excedam a capacidade que esta mesma comunidade tem para enfrentá-las somente com seus próprios recursos.

As dificuldades maiores residem na falta de compreensão, principalmente por ausência de conhecimento e, quando presente, de educação ambiental, dos níveis cumulativos "das alterações ambientais que se acumulam", inclusive, no seio das próprias comunidades diretamente envolvidas. Na medida em que os recursos vegetais naturais vão sendo explorados e paulatinamente exauridos, as dificuldades de utilização destes recursos vão aumentando (distâncias físicas entre os locais de extração e de utilização, por exemplo) de uma forma tal que as mesmas vão ficando impraticáveis, por conta do desequilíbrio das relações de custo-benefício, crescentemente negativas. Uma cadeia produtiva se mantém, mas sustentada em bases falsas, na medida em que cada vez mais vãoficando penalizados os atores a partir do início deste processo. Com o tempo, as rupturas se estabelecem, provocando dentre muitas coisas os fenômenos de migração, que na verdade são o reflexo da falta de capacidade que uma determinada comunidade tem para enfrentar uma crise (ou mais crises) somente com seus próprios recursos.

O fogo e o corte de lenha nos cerrados e nas caatingas nordestinas, por exemplo, continuam porque, de fato, poucas alternativas são conhecidas e explotadas e, porque, em condições de resistência de permanência no campo, homens e mulheres exploram as opções que a eles são, no momento, oferecidas ou impostas de uma certa maneira. Terminadas estas opções, porque os recursos não são renováveis por conta de questões de recorrência e de resiliência dos ecossistemas, a expulsão dos principais personagens se estabelece aos poucos e, o que é mais sério, se estabelecem as rupturas das ligações culturais entre as gerações diretamente envolvidas.

Por outro lado, as rupturas daquela cadeia "produtiva" não penalizam somente os pequenos coletores, ou os pequenos agricultores. Diferentemente do que ocorre no bioma da Caatinga, o principal fator de pressão e impacto ambiental sobre o bioma do Cerrado está nos modelos de ocupação do espaço e produção adotados pelo "negócio da agricultura", na matriz energética em implantação, na infra-estrutura de transportes que se desenvolve ali e nos próprios processos de expansão urbana. Os modelos deste negócio, principalmente têm relação estreita com os padrões de consumo e matrizes energéticas vigentes nos países altamente industrializados, sem levar em plena consideração os impactos econômicos, sociais e ambientais decorrentes para o Cerrado, sua população e o país como um todo (PEREIRA et al., 1998).

A ocupação dos cerrados brasileiros, e agora, os do Nordeste, como exemplo atual, acontece muitos anos na frente do domínio do conhecimento científico a respeito deles. Desta maneira, o empobrecimento genético (erosão genética) ocorre de modo acentuado e abrupto, por ocasião dos desmatamentos em grande escala para a abertura das fronteiras agrícolas horizontais, principalmente porque estes não consideram as ilhas de biodiversidade (tamanho e forma dos fragmentos) e os corredores de ligação (corredores ecológicos). Ao empobrecimento da diversidade biológica segue-se a fragilidade dos controles biológicos naturais, com a sua substituição pelos controles biológicos artificiais e pelos controles 
químicos, gerando desastres ecológicos com amplas repercussões econômicas e sociais de desagregação.

Segundo THOMAS (1994b), um desastre pode ser definido como uma ocasião de crise ou "stress" social, observável no tempo e no espaço, em que sociedades (comunidades, regiões, etc.) sofrem danos ou perdas físicas e alterações em seu funcionamento rotineiro. Tanto as causas como as consequiências dos desastres são produto de processos sociais que existem no interior da sociedade.

A relação da perda crescente da biodiversidade com a migração (êxodo rural) é inequívoca. Trata-se de formas de desastre.

Com relação à "teoria do risco", segundo REBELO (2001), toda ela se organiza em torno da seqüência de três conceitos: o de risco, propriamente dito, o de perigo, e o de crise (de desastre). Interpretações diferentes existem com relação a esta ordem de acontecimentos, bem como com as questões de vulnerabilidade associada, de uma forma tal que, para alguns, a presença do perigo não desencadeia o risco (Tricart, 1992; citado por REBELO, 2001), necessariamente, ou que, na ausência da vulnerabilidade, não haveria risco, por exemplo.

Nesta área o campo é fértil para considerações. Até que ponto os riscos naturais são puramente naturais? Os riscos ditos tecnológicos consideram todos os níveis diferentes da tecnologia que conhecemos? As questões da vulnerabilidade estão somente relacionadas à presença do homem, isto é, da espécie humana? Na visão de REBELO (2001), dificilmente se poderá imaginar um lugar da Terra onde o homem não esteja, não tenha estado, ou não possa vir a estar. Mesmo que lá não esteja, hoje, estará por perto e, mais tarde ou mais cedo, poderá vir a sofrer com algo de estranho que nesse lugar aconteça. Vulnerabilidade, portanto, é um conceito antropológico? As outras espécies que compõem a biodiversidade do Planeta não apresentam vulnerabilidade? Na biosfera, a vulnerabilidade de uma espécie não afeta a vulnerabilidade das outras?

Segundo CONTI (2002), as grandes áreas urbanas não são exclusivas para a desarmonia que se verifica entre a sociedade e a natureza. Desmatamentos, queimadas e mineração provocam efeitos também sobre a biodiversidade, empobrecendo-a. Com a continuação das práticas atuais e da formulação de políticas públicas associadas às questões de mandato (duração de gestões de governança), em um curto espaço de tempo as "perdas da biodiversidade" se incluirão no "ranking" dos eventos catastróficos, junto às que foram listadas por Bryant (1991; citado por CONTI, 2002), com direito, inclusive, de terem uma graduação de características e impactos como "grau de severidade", "extensão do evento (área)", "perdas econômicas", "efeito social", "impacto de longo prazo", dentre outras(s).

\section{O Principal Risco Natural do Nordeste: A Seca}

A seca no Nordeste do Brasil é um dos principais riscos naturais (recorrente), que pelas peculiaridades inclui-se no grupo dos riscos naturais climático-hidrológicos, segundo REBELO (2001).

A ausência parcial ou total das chuvas ou sua má distribuição, durante o período em que as precipitações deveriam ocorrer, é definida como seca. Ela pode ser meteorológica, quando está relacionada à queda na precipitação normal por um determinado período de tempo, na dependência de critérios que variam conforme as características climáticas das diversas regiões do mundo. Pode ser edáfica, quando está relacionada à falta de umidade que afeta o desenvolvimento e/ou a sobrevivência de culturas agrícolas, pastoris e florestais. Hidrológica, quando as deficiências se referem ao suprimento de água superficial ou subterrânea, levando-se em conta os intervalos de tempo entre o começo da ausência das precipitações e o decréscimo de água em rios, lagos e reservatórios. E, por fim, pode ser sócio-econômica, quando a mesma afeta a produção de bens de consumo, prejudicando a economia da região atingida.

A problemática climática do semi-árido está associada a vários aspectos. Dentre eles, podem ser citados: a enorme variabilidade espacial e temporal da precipitação (500 a $1800 \mathrm{~mm} / \mathrm{ano}$ ), a alta taxa de evapotranspiração potencial (maior que $2500 \mathrm{~mm} /$ /ano), as condições geológicas restritivas na maior parte das áreas (cristalino), o caráter intermitente dos rios (vazões nulas), os períodos de secas e cheias (migração, perda agrícola, inundações) e. principalmente, o uso múltiplo da água (abastecimento humano, irrigação, produção de energia, recreação, etc.).

O primeiro registro da seca no Nordeste do Brasil foi feito em 1559. Sua frequêencia é de mais ou menos nove por Século, uma a cada onze anos.

Nos séculos XVIe XVII, as secas não provocaram muitos impactos, devido ao número reduzido de habitantes e à abundância dos recursos naturais que minimizavam os seus efeitos, segundo BRITO GUERRA (1981). No entanto, a partirdo século XVIII, 1777-1788, restaram apenas $1 / 8$ do gado da Capitania do Ceará e, no período de 1877-1879, as secas ocasionaram a perda de mais de meio milhão de vidas em todo o Nordeste do Brasil.

No século passado, as principais secas do Nordeste do Brasil aconteceram em 1903-1904, 1908 (afetando o estado do Rio Grande do Norte, principalmente), $1915,1919,1930-1932,1942,1953$ (atingindo fortemente o estado do Rio Grande do Norte, novamente, e o estado da Paraíba), 1958, 1970, 1976, 1979-1983, 1987-1988, 1991-1993, 1995 e 1998. Neste Século, em 2002, um total de $194(87,4 \%)$ municípios do estado do Piauí decretaram "estado de emergência". 
Neste meio tempo, alguns órgãos governamentais foram criados para combater o fenômeno da seca, como se ele pudesse ser debelado: o Instituto de Obras Contra as Secas (IOCS), ainda na época do Império, o Instituto Federal de Obras Contra as Secas (IFOCS), quando aquele federalizou-se, o Departamento Nacional de Obras Contra as Secas (DNOCS), quase extinto em 2001-2002, a Superintendência de Desenvol vimento do Nordeste (SUDENE), extinta em 2002, quase substituída pela Agência de Desenvolvimento do Nordeste (ADENE), atualmente em processo de avaliação com vistas a um seu renascimento a partir de 2003. A conhecida "indústria da seca" começa a ser montada aos poucos, desde o período de colonização do Brasil, com a participação do poder público(imperiale presidencial) e de algumas iniciativas privadas, a despeito de se saber que há muito o problema reside no fato de que este fenômeno é absolutamente natural e que, por extraordinário que pareça, mais incomum é a falta dela, uma vezque em condições normais o período de chuvas no Nordeste do Brasil tem duração variando de quatro a seis meses, acontecendo de janeiro a abril (ou junho), chovendo pouco no restante do ano e que as precipitações anuais estão entre 500 a $800 \mathrm{~mm}$ nas áreas semi-áridas, podendo atingir menos de $400 \mathrm{~mm}$, em algumas áreas de vales interiores (CARVALHO, 1988).

Dois grandes climas ocorrem no Brasil, os que são controlados por massas de ar equatoriais e tropicais, e os que são controlados por massas de ar tropicais e polares. No primeiro grupo, o clima equatorial úmido (com convergência dos alíseos; bastante associado com a floresta amazônica), oclima tropical (com inverno seco e verão úmido, associado com o pantanal, florestas semideciduais de interior, cerrado, mata de babaçu, e com muitas das áreas de tensão ecológica do Nordeste brasileiro), o clima tropical semi-árido (com tendência a seco pela irregularidade da ação das massas de ar; muito associado com a caatinga) e o litorâneo úmido (influenciado pela massa de ar tropical marítima; associado, por sua vez, com a mata atlântica). No segundo grupo, o clima subtropical úmido (que afeta as costas orientais e subtropicais brasileiras, com o predomínio da massa de ar tropical marítima, associa-se com a mata atlântica do sudeste meridional, com as florestas subtropicais e com os campos sulinos).

A vocação pré-desértica do polígono das secas, segundo VASCONCELOS SOBRINHO (1978), está condicionada por um "equilíbrio ecológico instável decorrente do regime pluviométrico de baixo índice de precipitação e extrema irregularidade, dos solos rasos e com limitada capacidade de retenção de água, amplo fotoperiodismo e ventos secos e quentes com forte poder de desidratação". Aolado destas limitações naturais, a ação humana submete constantemente estes ambientes a níveis significativos de secundarização, de tal maneira que as condições ambientais se depreciam crescentemente, possibilitando a instalação (às vezes, a invasão biológica) de plantas com maior rusticidade. Um tipo de homogeneização florística se estabelece e, neste aspecto, as perdas da biodiversidade podem ser mais facilmente observadas.

\section{Um dos Principais Riscos Antrópicos: O Desma- tamento.}

No Nordeste brasileiro, a conversão de vegetação nativa para atividades agropecuárias remonta aos Séculos XVI e XVII. Segundo COIMBRA FILHO \& CÂMARA (1996), os primeiros desmatamentos estão associados com as "prováveis rotas das frentes de gado no período de 1500-1700" (Figura 1). Segundo o MEC (1959; citado também por COIMBRA FILHO \& CÂMARA, 1996), as atividades econômicas do Século XVIII relacionam diretamente aquela conversão por culturas de cana-de-açúcar no litoral atlântico nordestino e na baixada maranhense, bem como a pecuária ao longo das margens do rio São Francisco, principalmente no estado da Bahia, e nas margens do médio e baixo Parnaíba, nos estados do Piauí e do Maranhão. A mineração, mais localizada no centro da Bahia àquela época, também pode estar associada com estes grandes e paulatinos desmatamentos ao longo da história de ocupação do Nordeste do Brasil.



Figura 1 - Prováveis Rotas das Frentes de Gado - período de 1500 a 1700 (Séculos XVI e XVII) (COIMBRA FILHO \& CÂMARA, 1996). 
Em termos de Brasil, com base em estimativas de 2002 do Ministério do Meio Ambiente (MMA), a cobertura vegetal original se encontra comeste "status" em apenas 56,6\% (cerca de 483.990.572ha) do território brasileiro. Isto significa, que em um período de 500 anos, foram desflorestados um total de $43,4 \%$ (370.749.728ha). Neste período, a taxa de desmatamento foi de 0,2\%/ano. No período de 1990-1995, entretanto, esta taxa, chegou aos 0,5\%/ano. Desta forma continuando, bastariam 200 anos para o território brasileiro ser completamente desflorestado.

Em 1985 (DIAS, 1994) o Brasil já possuía 37\% de paisagens antrópicas e $56 \%$ de paisagens naturais manejadas. A taxa anual de crescimento das pastagens plantadas e das pastagens nativas manejadas era de $1,12 \%$. As culturas anuais, reflorestamentos e culturas perenes cresciam anualmente com uma taxa de $1,44 \%$ (DIAS, 1994).

Segundo o IBAMA (2002, informação pessoal)e o PNF (2002, informação pessoal), dos $47,8 \%$ (408.444.900ha) da Amazônia brasileira, restam $85 \%$. Do Pantanal, com 1,6\% (14.016.600ha) de ocupação, restam ainda $90 \%$ da sua cobertura vegetal anterior.

Se $15 \%$ ou $10 \%$ da floresta amazônica e do pantanal, respectivamente, ainda não são comprometedores, para os outros Biomas a situação começa a ficar muito crítica. Para o Cerrado, o segundo maior bioma brasileiro, dos $21,5 \%$ (183.603.700ha), apenas $45 \%$ corresponde à estimativa de cobertura vegetal atual. Sua vocação desenvolvimentista para abrigar grandes centros urbanos em plena expansão, Goiânia e Brasília, capitais de Goiás e do Brasil, respectivamente, e a cidade de Palmas, capital do Tocantins, bem como sua vocação para a agroindústria, por conta dos grandes rebanhos, do arroz (de sequeiro), da soja, do milho e das últimas e extensas fronteiras agrícolas horizontais do país, estão diretamente associadas. Dos 12,4\% (105.733.400ha) que a caatinga, exclusiva do Nordeste, ocupa, cerca de $30 \%$ apenas encontram-se não convertidas totalmente, porque neste caso, em função da sua história de utilização, por conta da agricultura itinerante ao longo de mais de 300 anos de ocupação, com baixa tecnologia, muitos inferem que não existem mais caatingas primárias legitimamente, senão remanescentes de caatinga de oito, doze ou de vinte anos (CASTRO et al., 2003), por exemplo.

Para a mata atlântica e para os campos sulinos, enquanto Biomas, os números são assustadores, principalmente para a primeira. Dos $13,3 \%(113.980 .300 \mathrm{ha})$, apenas $7,3 \%$ da mata atlântica encontra-se intacta, praticamente enclausurada em fragmentos florestais determinados por legislação ambiental, ou em algumas e poucas unidades de conservação. Dos $1,8 \%$ (15.352.200ha) que antes eram ocupados pelos campos sulinos, restam apenas $10 \%$.
Com relação ao estado do Piauí, como um exemplo, os pedidos de desmatamentos tramitados na Gerência Executiva Estadual do Instituto Brasileiro do Meio Ambiente e dos Recursos Naturais Renováveis (IBAMA) são sempre maiores do que os que são autorizados. No período de 1999-2002, 13,5\% de desmatamento na caatinga foram autorizados, em média, e $20,4 \%$ para o cerrado e para as áreas de transição, separadamente. As áreas de cerrado, atualmente, são mais desmatadas que as áreas de caatinga, e os números parecem refletir, que apesar das variações anuais de autorização, existe uma certa proporcionalidade entre o que é solicitado e o que é autorizado. Ainda mais, provavelmente, as autorizações de desmate têm grande relação com o baixo nível de conhecimento que se tem sobre a biodiversidade desses ecossistemas.

Nas áreas de transição, que apresentam contatos de cerrado e de caatinga, que contêm encraves de cerrado ou de caatinga, ou que apresentam áreas consideráveis de ecótonos ou áreas de tensão ecológica (RIVAS, 1996), pouco se sabe quanto do cerrado ou da caatinga, por exemplo, está desaparecendo. Pior, não se conhece quase nada de iniciativas de recuperação de áreas com florestamentos, reflorestamentos, reposição vegetal, enriquecimento com essências nativas, ou com estudos e pesquisas para a repartição dos benefícios da biodiversidade potencial. Quando se tem notícia de um projeto de reflorestamento, o mesmo ocorre em áreas que têm cobertura vegetal nativa. Muito raramente é aplicado para áreas que deveriam ser recuperadas, no lugar de abandonadas. Outras vezes trata-se de projetos de manejo, mas manejo de uma única espécie vegetal, como se anteriormente somente esta mesma espécie povoasse unicamente a área, motivo de intervenção.

Desta forma, a despeito das autorizações oficiais, a depreciação da cobertura vegetal natural continua a suceder. A ainda abundância relativa dos recursos naturais frente às atuais taxas de ocupação demográfica rural no estado do Piauí, adia para um futuro incerto os níveis altos de vulnerabilidade, que inexoravelmente passarão a ser comprometedores.

\section{Outro dos Principais Riscos Antrópicos: O Fogo}

Neste aspecto, a avaliação, inclusive dos órgãos oficiais é restritiva, senão absolutamente inócua, a despeito dos domínios atuais que se têm da tecnologia ao nível de cobertura por satélite, uma vez que os sensores do NOAA-12, por exemplo, captam "focos de calor", simplesmente, desde que os mesmos tenham uma área mínima de $100 \mathrm{~m}^{2}$. Entretanto, nem todo foco de calor está relacionado com "incêndio florestal", uma vez que o mesmo não discrimina estes mesmos incêndios, das queimadas autorizadas pelo IBAMA, 
em consonância com a legislação ambiental, relacionadas à renovação de pastos para a pecuária extensiva, ao corte da cana-de-açúcar, à renovação das culturas de subsistência (agricultura familiar), e aos grandes empreendimentos de conversão (vegetação nativa versus grãos, principalmente soja), devidamente licenciados pelos órgãos ambientais a partir dos estudos e relatórios feitos, em geral incompletos e muito deficientes, de impacto ambiental, mas aprovados pelos atuais níveis de cultura de todo o conjunto da sociedade civil.

No estado do Piauí, o fogo está associado a algumas causas como os acidentes, a baixa tecnologia agropecuária (cerca de $90 \%$ dos casos) para a roça de subsistência e de renovação de pastagem nativa, aos caçadores (como armadilhas para animais) e a liberação de novas áreas para as atividades agropecuárias, principalmente no sudoeste do Estado.

Infelizmente, não há ainda condições de se estimar o tamanho das áreas queimadas, senão em áreas protegidas (unidades de conservação, UCs), porque neste caso o tamanho das mesmasé conhecido (IBAMA 2002, informação pessoal). Mesmo assim, duvidamos, pois nem sempre a área total de uma UC nãoé de toda vez atingida.

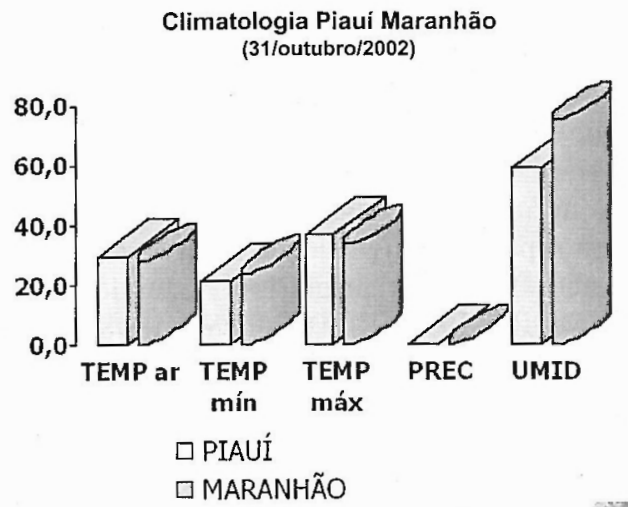

Figura 2 - Climatologia do Piauí e do Maranhão em 31/10/2002. Temperatura do Ar, Temperaturas Mínima e Máxima e Umidade Relativa do Ar.
Assim, no Nordeste do Brasil, de modo similar ao que acontece em todo o território brasileiro, principalmente no "arco do fogo da Amazônia", localizado nos estados de Mato Grosso e do Pará, no entorno da Amazônia oriental, tanto as queimadas (fogo autorizado), quanto os incêndios florestais (fogo descontrolado) destroem, anualmente, grandes áreas de vegetação nativa no Brasil, sendo uma das principais ameaças aos ecossistemas brasileiros, com inclusividade para as suas megadiversidades ainda pouco conhecidas.

Durante todo o ano, as temperaturas médias (média das máximas, média das mínimas e média das médias) para o Nordeste do Brasil são muito altas, variando de 24 a $32^{\circ} \mathrm{C}$. Nos meses de junho a setembro elas diminuem, mas em geral muito pouco. A partir de abril as precipitações médias diminuem vertiginosamente. Assim, altas temperaturas e baixas precipitações, apesar da umidade relativa variar em torno de 60-80\%, a frequiência de focos de calor aumenta consideravelmente. A Figura 2 mostra um exemplo disto para um dia típico em termos da climatologia do Piauí e Maranhão.

Nos meses de agosto a novembro o número de focos de calor varia abruptamente de 2.000 para mais de 16.000 focos. No período de 1998 a 2002, os anos de 2001-2002 se destacam negativamente para o Nordeste do Brasil. Como grande parte dos fogos autorizados se alastram, assumindo com freqüência o "status" de incêndios (fogos descontrolados), até algumas unidades de conservação de uso indireto são fortemente impactadas no Sudoeste do estado do Piauí. A Figura 3 mostra um flagrante disto na Estação Ecológica de Uruçuí-Una.

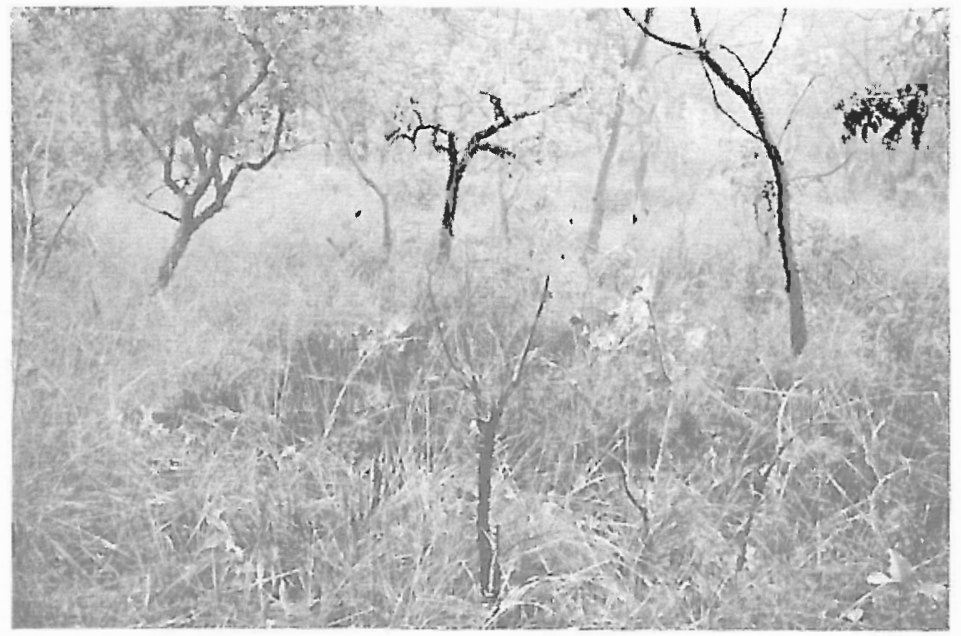




\section{Outro ainda dos Principais Riscos Antrópicos: A Desertificação.}

Ofenômeno da desertificação refere-se à degradação da terra nas zonas áridas, semi-áridas e subúmidas secas, todas, com exceção das polares e subpolares, resultante de vários fatores, incluindo as variações climáticas e as atividades humanas, nas quais a razão entre a precipitação anual e a evapotranspiração potencial está compreendida entre 0,05 e 0,65 (SAMPAIO \& SAMPAIO, 2002).

Sua avaliação, segundo (RODRIGUES et al., 1995), considera tradicionalmente os seguintes indicadores: 1) Densidade Demográfica, 2) Sistema Fundiário, 3) Tempo de Ocupação, 4) Mineração, 5) Erosão, 6) Perda de Fertilidade, 7) Pecuarização, 8) Estagnação Econômica, 9) Mecanização, 10) Salinização, 11) Evolução da População, 12) Bovinocultura, 13) Caprinocultura, 14) Ovinocultura, 15) Área de Preservação, 16) Susceptibilidade Climática, 17) Uso de Defensivos Agrícolas, 18) Qualidade da Água,e 19) Área Agrícola. Combase nestes indicadores, graus de intensidade do fenômeno podem ser inferidos qualitativamente como: "muito grave", se 15 ou mais desses indicadores puderem estar associados; "grave", se 11 a 14 indicadores forem envolvidos; e "moderado", se 6 a 10 indicadores forem, por sua vez, relacionados.

Com base nas estimativas de ocorrência da desertificação no Nordeste do Brasil (RODRIGUES, 2003, informação pessoal), $17,2 \%(9.859 .500 \mathrm{ha})$ da região Nordeste já apresentam o fenômeno da desertificação como "status" de "muito grave"; $14,3 \%$ (8.187.000ha), com o "status" de "grave", e 68,6\% (39.389.700ha), por sua vez, com o "status" de "moderado". Em termos de susceptibilidade ao fenômeno, estimativas de 23.864.400,07ha, classificadas como "muito alta", de 38.402.971,45ha como "alta" e de 34.688.951,22ha como "moderada" são indicadas.

Entretanto, as dimensões conceitual, científica e política da desertificação no Nordeste do Brasil são desagregadoras, uma vez que o problema avança e as pessoas continuam a discutir conceitos, escalas de trabalho, tamanhos da região semi-árida, etc. A Figura 4 mostra uma das áreas mais afetadas no município de Gilbués (PI) pela degradação ambiental, uma das áreas de tensão ecológica do estado do Piauí, no contato do Semi-Árido com o Subúmido piauiense.

A Figura 5 mostra um trecho de vegetação de cerrado no interior da Estação Ecológica de Uruçuí-Una (Baixa Grande do Ribeiro, PI) começando a ser afetada, localizada ao Norte do município de Gilbués (PI), e a Figura 6 ilustra os efeitos da degradação ambiental em uma área localizada no município de Santa Filomena (PI), a Oeste de Gilbués (PI).

Com relação ao conceito, o que é mesmo desertificação? Que diferenças há entre desertificação e arenização? (MARCHIORI, 1992). Esterilização ambiental? (REIS, 1968). Desertização? Aridização versus Aridificação?(BAUMER, 1987). Savanização versus Savanificação? (AB'SÁBER, 1977). Desertificação sensu lato e Desertificação sensu stricto?

Com relação às escalas de trabalho, se macro-regional, regional ou local, o que se tem conhecimento é de que há pouco ou nenhum investimento para estudos de campo, de experimentação, forçando com que as abordagens considerem quase sempre o fenômeno apenas ao nível de pequenas escalas. Como quase não há dados primários, fazendo exceção MORTIMORE(1994), RODRIGUES (1998) e SALES

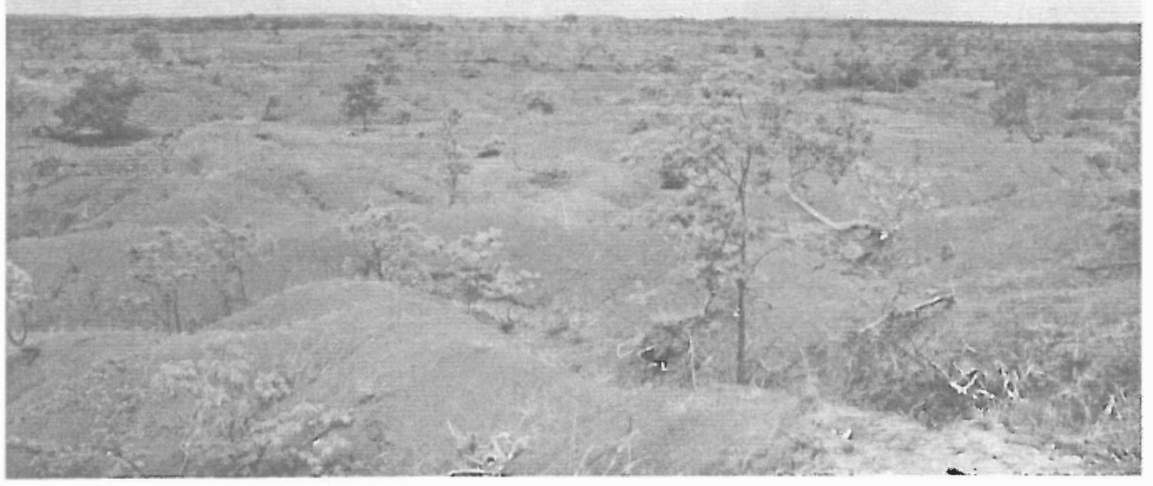

Figura 4 - Área de Cerrado em processo acentuado de Degradação Ambiental (Gilbués, PI). Foto do Autor. 


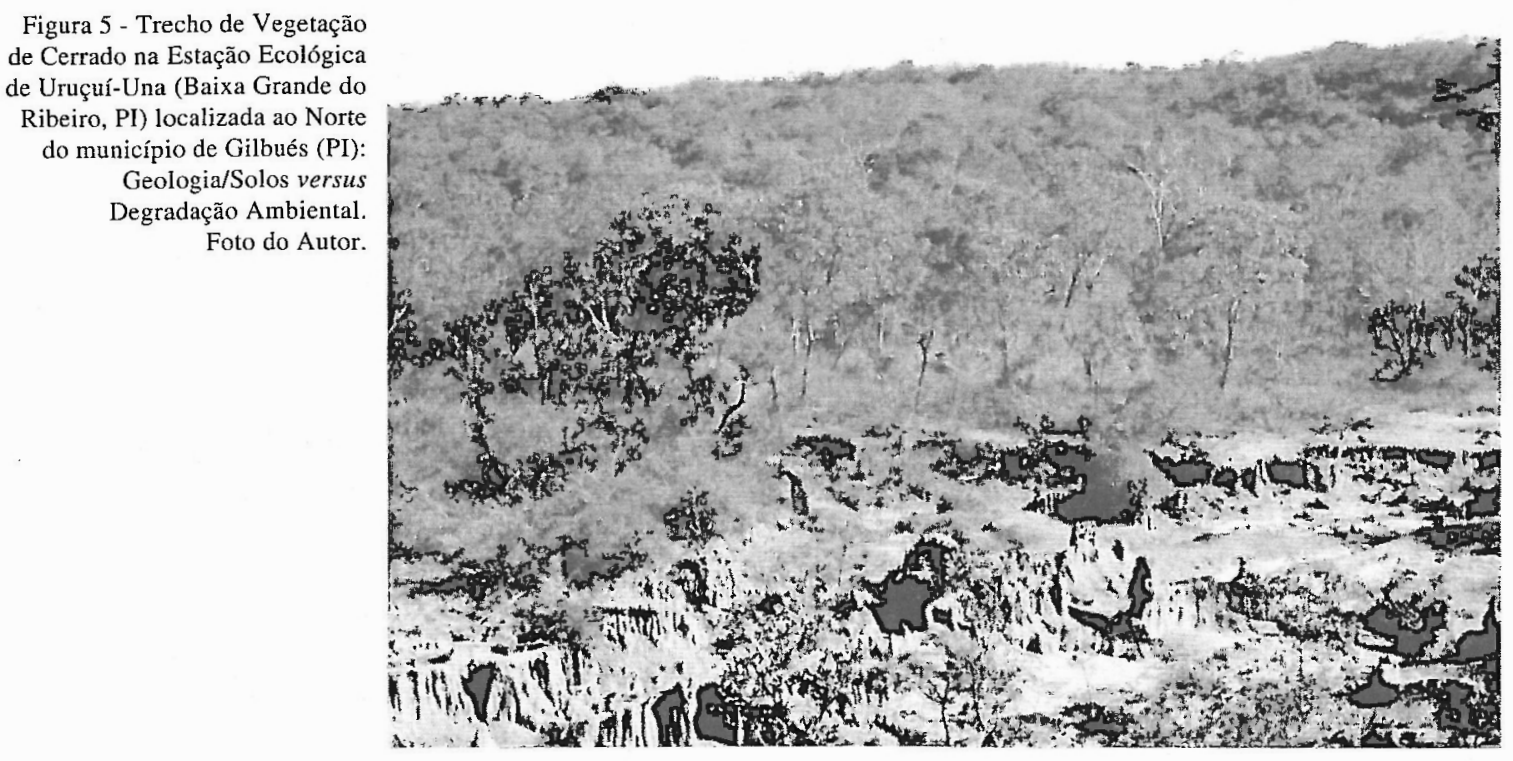

(1998, 2002), para Gilbués (PI), por exemplo, os dados secundários que existem, porque incompletos, não sistemáticos e generalistas, são muito inclusivos (muito regionais).

Com relação ao tamanho do semi-áridonordestino, pelo menos quatro critérios são considerados. Uma isoieta da média de 800 $\mathrm{mm}$ (SUDENE 1999, adaptado por GOMES \& CARVALHO, 2002), ou uma isoieta da moda de $800 \mathrm{~mm}$ de precipitação anual (SOUZA et al., 1994), demarcariam o polígono das secas. Com o primeiro critério o "polígono das secas" seria maior, portanto, mais inclusivo. Com o segundo critério, o tamanho do Semi-Árido diminui. Com este, alguns municípios passam a ter potencialmente menos recursos para investimentos "em nome da seca". De outro modo, conforme a elaboração dos "planos de emergência" que é feito pela Defesa Civil dos Estados, ou do "rateio de investimentos" que é discutido pela Associação dos Prefeitos Municipais, os dois, quando em períodos de calamidade, demarcam também tamanhos diferentes para o mesmo semi-árido do Nordeste. Programas estatais e do Terceiro Setor para a convivência com a seca substituem legitimamente os antigos "programas para o combate à seca". Entretanto, é preciso se estar muito atentos para que a chamada "indústria da seca" não se transforme em "indústria da desertificação".

De acordo com dados adaptados do IBGE (1975, $1985,1991,1993), 76.505 .909 \mathrm{ha}(20,9 \%)$ do Semi-Árido se encontram desertificados e $10,6 \%$

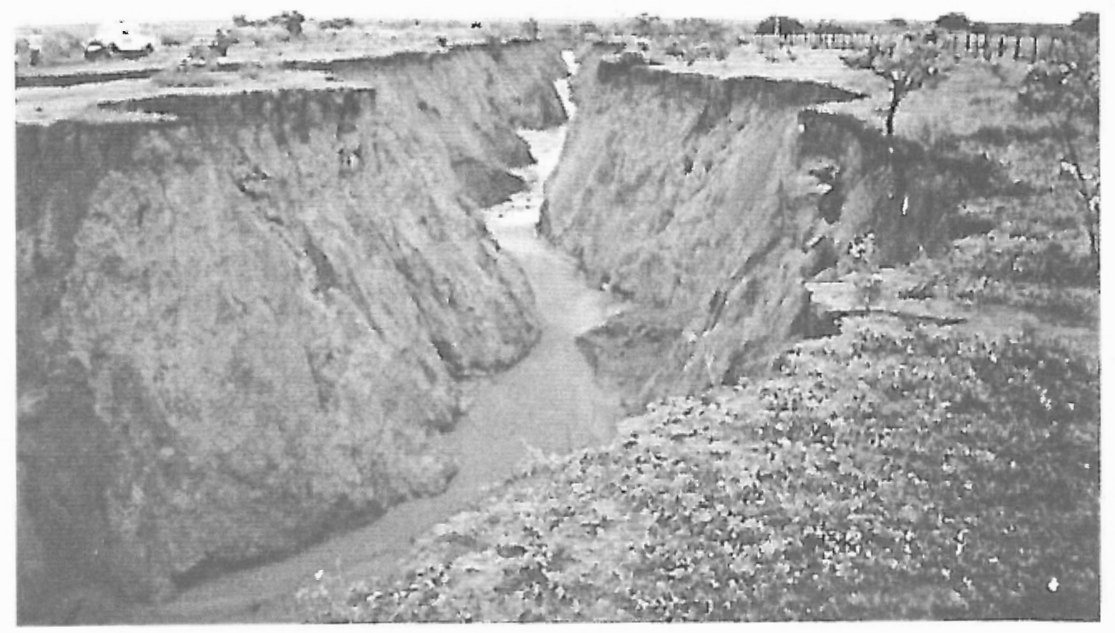

Figura 6 - Voçoroca gigante em área cultivada de Cerrado (Santa Filomena, PI) localizada a Oeste do Município de Gilbués (PI): Desmatamento versus Degradação Ambiental. Foto do IBAMA. 
(3.994.664hab) já se encontram afetados em termos de população. Por estado (divisão política estadual), por exemplo, $31 \%$ dos 11.009 .164 ha do Semi-Árido do estado do Ceará se encontram afetados pela desertificação, envolvendo já $14 \%$ da população do mesmo (862.368hab). No Rio Grande do Norte, 26\% de áreae $12 \%$ da população já se encontram diretamente afetados. Na Paraíba, $25 \%$ da área e $13 \%$ da população se encontram da mesma maneira. No Piauí, dos 11.828.027ha do semi-árido piauiense, $2.767,765 \mathrm{ha}$ (23\%) se encontram afetados pela desertificação sensu lato, já afetando, entretanto, cerca de $15 \%$ (376.197hab) da população atual.

De acordo com RODRIGUES et al. (1995), o estado do Maranhão ainda não apresenta suscepțibilidade ao fenômeno da desertificação, por isso, apenas $67.362 .494 \mathrm{ha}(55,1 \%)$ do Nordeste do Brasil se encontram susceptíveis a este fenômeno especial de degradação ambiental. O estado do Sergipe só a apresenta com grau "moderado", relacionada a uma área de 684.299ha $(31,4 \%)$ da área total do mesmo Estado. Os estados do Rio Grande do Norte (com $80,5 \%$ ), Pernambuco (com 75,2\%), Paraíba (com $70,3 \%$ ) e o Ceará (com 59,7\%) de áreas susceptíveis à desertificação são os campeões, com apresentação de todos os graus: "muito grave", "grave" e"moderado".

Infelizmente, apenas um levantamento florístico e fitossociológico significativo foi realizado em uma área de degradação ambiental no município de Gilbués (PI) (RODRIGUES, 1998), considerada de forma generalizada como um dos principais núcleos de desertificação do Nordeste brasileiro, eque foi refutado como tal por MORTIMORE (1994) e por SALES (1998). A desertificação como um caso especial de degradação ambiental, leva inexoralmente ao empobrecimentobiológico, com efeitos, inclusive, à extinção de espécies, ao menos ao nível local. Entretanto, como as áreas afetadas tendem a ser cada vez mais crescentes porque pouco ou quase nada se faz, essa extinção de espécies vai ter visibilidade somente em um futuro próximo.

\section{As Perdas da Biodiversidade e as Estratégias de Conservação}

Com base em dados do IBAMA (2002, informação pessoal) e IBGE (2002) um total de 108 espécies de vegetais superiores estão ameaçadas de extinção ao nível de Brasil. Conforme as categorias de risco que foram estabelecidas pela Union International Conservation World (UICN), duas espécies estão provavelmente extintas, consideradas assim porque são espécies definitivamente não encontradas na natureza nos últimos 50 anos, 41 espécies estão "em perigo", 35 são "vulneráveis", 25 são "raras", e cinco espécies com categoria de risco "indeterminada". Para a fauna (animais) este tipo de monitoramento é melhor, de um lado, porque fauna tem mais visibilidade (porque tem maior apelo visual) do que flora (vegetais), por extraordinário que pareça. Para muitos, a vegetação é "fundo de palco". De outro lado, porque de um modo geral a extinção da fauna se sucede à extinção da flora, principalmente quando se leva em conta a relação plantas (autótrofos) e animais (heterótrofos).

Aqueles números, por sua vez, certamente estão muito defasados, porque, pelo menos em CASTRO (1994), na atualização do conhecimento da flora lenhosa (árvores e arbustos) dos cerrados do Brasil, listou $343(19,6 \%)$ espécies das 1.753 arroladas naquela ocasião, que tinham ocorrência em apenas uma das amostras de um universo de 78 áreas e 145 "checklists" avaliados.

Em termos de espécies animais ameaçadas de extinção (IBGE, 2002), um total de 220 espécies está ameaçado, do qual oito espécies estão extintas no território brasileiro, uma "extinta na natureza", 35 espécies "criticamente em perigo", 40 em "perigo", 62 "vulneráveis", 17 espécies com "baixo risco", e 57 "sem classificação" com relação à sua categoria de risco. Daquelas 220 espécies, 67 são de mamíferos, 110 são de aves, 9 são de répteis, e 29 são de insetos.

Para o Brasil, conforme aquela mesma base de dados, de um total estimado de 518 espécies de mamíferos, $67(12,9 \%)$ estão ameaçadas de extinção. De um total estimado de 1.677 espécies de aves, 110 $(6,6 \%)$ estão ameaçadas de extinção, e de um total de 468 espécies brasileiras de répteis, como mais um dos principais exemplos, $9(1,9 \%)$ espécies estão comprometidas em termos de total desaparecimento.

Estimativas desta natureza, infelizmente, não existem para as regiões brasileiras, nem sequer para os estados, apesar de alguns deles, como São Paulo, Minas Gerais e Pernambuco, porque contam com mais recursos financeiros, com mais organizações ambientais não-governamentais e com fundações de amparo à pesquisa mais atuantes e mais respeitadas pelo poder público em termos de manutenção de políticas de ciência e tecnologia, por exemplo, têm já iniciado este exercício de prospecção da biodiversidade, principalmente em termos da abordagem da diversidade de ecossistemas, até porque, por ter maior visibilidade, mais fácil conquista adeptos e parceiros de todos os níveis.

Ao nível de Brasil, ainda, um dos avanços consideráveis tem sido feito a partir da Convenção sobre Diversidade Biológica, adotada e aprovada durante a Conferência das Nações Unidas sobre Meio Ambiente e Desenvolvimento, em 1992, e ratificada em 1994. As premissas são de que "a biodiversidade representa uma das mais importantes bases do desenvolvimento 
cultural, social e econômico da espécie humana" e de que "a nossa sobrevivência no Planeta depende da sua conservação e utilização sustentável".

Assim, como instrumentos para a formulação de políticas públicas respaldadas no estado da arte (atualizado) do conhecimento sobre a biodiversidade e na "expertise" dos pesquisadores brasileiros, vários "workshops" foram realizados, por Bioma, para gerarem, cada um, mapas temáticos de indicação de áreas prioritárias para a conservação e utilização sustentável da biodiversidade. Além disso, como outras estratégias para a conservação, iniciativas foram feitas para a criação de Reservas da Biosfera. No Brasil, a Reserva da Biosfera da Mata Atlântica, a Reserva da Biosfera do Cerrado (Fases I, II e III), a Reserva da Biosfera do Pantanal e a Reserva da Biosfera da Caatinga foram efetivamente criadas. Outro instrumento importante que aos poucos se dissemina no país refere-se aos "zoneamentos ecológico-econômicos", os chamados ZEEs, coordenados estes pela Secretaria de Políticas para o Desenvolvimento Sustentável do Ministério do Meio Ambiente (MMA). As Áreas Prioritárias e as Reservas da Biosfera, por sua vez, são coordenadas pela Secretaria de Biodiversidade e Florestas do mesmo órgão ministerial, o MMA.

De outro modo, a divisão dos Biomas em ecorregiões, para efeitos de propostas de manejo biorregional (MILLER, 1997), tem definida algumas das ecorregiões para o Brasil (WWF, 2000), que erroneamente considerou a Caatinga e o Cerrado como se tivesse, cada um, apenas uma ecorregião. Para a Caatinga, VELLOSO et al. (2002) corrigiu esta falha. Para o Cerrado, a Diretoria de Ecossistemas do IBAMA e o Programa de Pós-Graduação de Ecologia da Universidade de Brasília (UnB), deverão apresentar ainda este ano, uma propositura de delimitação de ecorregiões para este Bioma.

A idéia de ecorregião parte da compreensão de que "qualquer que seja a mudança, a questão principal éo equilíbrio de escalas, ou seja, encontrar os melhores locais para conservar a natureza e os recursos naturais, sem desprezar bens e serviços que possam ser produzidos e desenvolvidos sustentavelmente" (MILLER, 1997).

Como as unidades de conservação são e nunca devem ser encaradas como restritivas do desenvolvimento de um povo, em qualquer lugar do mundo, elas formam o conjunto de células para todas as estratégias, não importando se a perspectiva é de reserva da biosfera, de ecorregião, de corredores ecológicos, de áreas prioritárias, ou deZEEs. Entretanto, como qualquer desenvolvimento é impactante, pela sua própria natureza, é preciso se pensar em estimulálo cada vez mais, porque a espécie humana demanda, mas levando em conta a ampliação e o tamanho dessas unidades de conservação, porque ainda são comprometedores os seus aspectos de representatividade, principalmente em termos de Brasil, por conta do seu tamanho territorial, da sua localização tropical, preponderantemente, e por conta das diversidades biológicas e "hotspots" que contém.

No Brasil, as unidades de conservação são classificadas em dois tipos de uso: Unidades de Proteção Integral (Estação Ecológica, Reserva Biológica, Parque Nacional, Monumento Natural e Refúgio da Vida Silvestre) e Unidades de Uso Sustentável (Área de Proteção Ambiental, Área de Relevante Interesse Ecológico, Floresta Nacional, Reserva Extrativista, Reserva de Fauna, Reserva de Desenvolvimento Sustentável e Reserva Particular do Patrimônio Natural) (MMA, 2000). Com base em dados do IBGE (2002), o país possui 217 unidades de conservação federais das quais, 94 são de "proteção integral" e 123 de "uso sustentável". A Amazônia, com 81 unidades, o Cerrado com 35, e a Mata Atlântica com 67 unidades de conservação são os Biomas que se destacam por possuírem os maiores números de unidades de conservação, entretanto, com "tudo isto", apenas $9,06 \%, 2,09 \%$ e $2,36 \%$, respectivamente, são potencialmente protegidos. Nem as Zonas Costeiras, que detêm 17 unidades de conservação, não protegem, através delas, mais do que $12,63 \%$ da sua área. Os ecótonos (Caatinga-Amazônia, Cerrado-Amazônia e Cerrado-Caatinga), espaços ecossistêmicos que provavelmente encerram respostas para importantes problemas e processos ecológicos que ainda vão ser compreendidos pela ciência, com 6 unidades de conservação, em todo o país, não protegem mais do que $10,98 \%$ dos seus espaços eco(geo)políticos.

Questões de estimativas de áreas de ocupação das formações vegetais (espelhos do clima), como um exemplo, são relevantes porque a partir delas pode-se pensar na ampliação de unidades de conservação ou criação de unidades de uso direto ou indireto para a conservação, manutençãodos serviços essenciais da natureza e repartição dos benefícios da biodiversidade. OBrasil, como um país de megadiversidade, não pode continuar a possuir no Cerrado, segundo PÁDUA \& DIAS (1998), apenas 200 unidades de conservação que cobrem apenas $1,6 \%$ da extensão territorial do Bioma, das quais 130 delas têm menos de 1.000ha, sendo de tamanho insuficiente para garantir a conservação da biodiversidade in situ.

A situação na caatinga, exclusiva do Nordeste do Brasil, é semelhante. Apenas $6,2 \%$ do polígono das caatingas estão dentro de unidades de conservação e destas, apenas $36,6 \%$ em unidades de uso indireto (parques nacionais, reservas biológicas e estações ecológicas), segundo TABARELLI et al. (2000). Estes números para a caatinga e aqueles para 0 cerrado estão muito aquém dos $10-15 \%$ considerados 
como os mínimos para conservar a diversidade biológica de biotas tropicais.

Noestado do Piauí, a situação nãoé muito diferente. Apenas $6,1 \%$ do território piauiense ( $1,0 \%$ da Região Nordeste) estão protegidos em unidades de Uso Indireto (Proteção Integral), enquanto que 12,7\% ( $2,1 \%$ da Região Nordeste) estão protegidos em unidades de Uso Direto (Uso Sustentável). Ver as

\section{Tabelas 1 e 2.}

Em termos de Reservas Particulares do Patrimônio Natural (RPPNs), apenas $0,06 \%$ da Região Nordeste está protegido. Os atuais $91.530,40 \mathrm{ha}$ em termos de RPPNs nordestinas é muito tímido, mas refletem um ponto muito positivo, porque demonstram que proprietários particulares começam a internalizar a importância e necessidade da conservação ambiental. Ver a Tabela 3.

As estimativas de áreas de ocupação da végetação do estado do Piauí variam muito, na medida em que as mesmas tem sido feitas por tipo vegetacional e, portanto, com a inserção de níveis significativos de sobreposição (CASTRO, 2003). Para a Caatinga (Figura 7), os números variam de 5.266.390ha (21\%) a 9.360.000ha (37,3\%). Para o Cerrado (Figura 8), as estimativas variam de $5.227 .600 \mathrm{ha}(20,8 \%)$ a 8.350 .000 ha $(33,3 \%)$. Neste caso, os números, ou referem-se a áreas de domínio, áreas de contato, ou áreas agricultáveis, influenciados estas últimas pela importância que os cerrados estão atualmente assumindo na perspectiva desenvolvimentista em curso. Para a vegetação das áreas de transição (Figuras 9e 10), as estimativas variam de $1.634 .700 \mathrm{ha}(6,5 \%$, transição de cerrado com floresta semidecídua) a 12.823.270ha $(51,1 \%$, transição de caatinga, cerrado, carrasco e floresta semidecídua).

Com base nestas estimativas para o Piauí e se $10 \%$ destas áreas fossem incluídas em unidades de conservação de uso indireto (áreas de proteção integral), com base no déficit atual de 3,9\%, áreas de 205.389,21 a $365.040,00 \mathrm{ha}$ poderiam ser adicionadas em termos de Caatinga. Áreas de 203.876,40 a 325.650.00ha poderiam ser acrescentadas em termos de Cerrado. Por sua vez, áreas de 63.753,3 a 500.107,53ha poderiam ser somadas em termos de Ecótonos (Áreas Transicionais ou Áreas de Tensão Ecológica). Com base no mesmo tipo de raciocínio, se $20 \%$ destas

\begin{tabular}{l|c|c|c|r|r}
\hline Tipo Unidades & Fed & Est & Mun & Área (ha) & Biomas/Ecossistemas \\
\hline $\begin{array}{l}\text { Unidades de } \\
\begin{array}{l}\text { Conservação } \\
\text { de Uso Indireto }\end{array}\end{array}$ & $\mathbf{8}$ & $\mathbf{1}$ & $\mathbf{7}$ & $\mathbf{1 . 5 3 7 . 9 5 4 , 3 5}$ & $\begin{array}{r}\text { Cerrado, Caatinga, Transição } \\
\text { Cerrado/Caatinga, Mata Ciliar, Áreas } \\
\text { Antropizadas e Áreas Urbanas de Lazer }\end{array}$ \\
\hline
\end{tabular}

Tabela 1 - Unidades de Conservação de Uso Indireto (Piauí) (MOURA FÉ, 2002, informação pessoal) Fed (Administração Federal), Est (Estadual) e Mun (MunicipaI).

\begin{tabular}{|c|c|c|c|c|c|c|}
\hline $\begin{array}{l}\text { Tabela } 2 \text { - Unidades de } \\
\text { Conservação de Uso Direto }\end{array}$ & Tipo Unidades & Fed & Est & Mun & Área (ha) & Biomas/Ecossistemas \\
\hline $\begin{array}{r}\text { (Piauí) (MOURA FÉ, 2002, } \\
\text { informação pessoal) Fed } \\
\text { (Adrministração Federal), } \\
\text { Est (Estadual) e Mun }\end{array}$ & $\begin{array}{l}\text { Unidades de } \\
\text { Conservação } \\
\text { de Uso Direto }\end{array}$ & 3 & 8 & 3 & $3.182 .107,23$ & $\begin{array}{l}\text { Cerrado, Caatinga, Transição } \\
\text { Cerrado/Caatinga e Mata Ciliar }\end{array}$ \\
\hline
\end{tabular}
(Municipal).

\begin{tabular}{l|c|r|r}
\hline Estado da Federação & Número & Área Total (ha) & Biomas/Ecossistemas \\
\hline Alagoas & 7 & $\mathbf{6 1 0 , 5 8}$ & Mata Atlântica \\
\hline Bahia & 44 & $\mathbf{3 2 . 4 9 2 , 3 1}$ & $\begin{array}{r}\text { Mata Atlântica, Caatinga e } \\
\text { Cerrado (Campo de Altitude) }\end{array}$ \\
\hline Ceará & $\mathbf{8}$ & $\mathbf{8 . 8 4 2 , 7 2}$ & Caatinga e Restinga \\
\hline Maranhão & 11 & $3.738,27$ & $\begin{array}{r}\text { Floresta Amazônica, } \\
\text { Manguezal e Cerrado }\end{array}$ \\
\hline Paraíba & 8 & $\mathbf{6 . 6 5 2 , 6 2}$ & Mata Atlântica e Caatinga \\
\hline Pernambuco & 3 & $1.586,70$ & Mata Atlântica e Caatinga \\
\hline Piauí & 5 & $34.675,03$ & $\begin{array}{r}\text { Cerrado, Caatinga e Transição } \\
\text { Cerrado/ Caatinga/Carrasco }\end{array}$ \\
\hline Rio Grande do Norte & 3 & $2.950,17$ & Cerrado e Caatinga \\
\hline Sergipe & 0 & $\mathbf{0 , 0}$ & \\
\hline & & $\mathbf{9 1 . 5 3 0 , 4 0}$ & \\
\hline
\end{tabular}




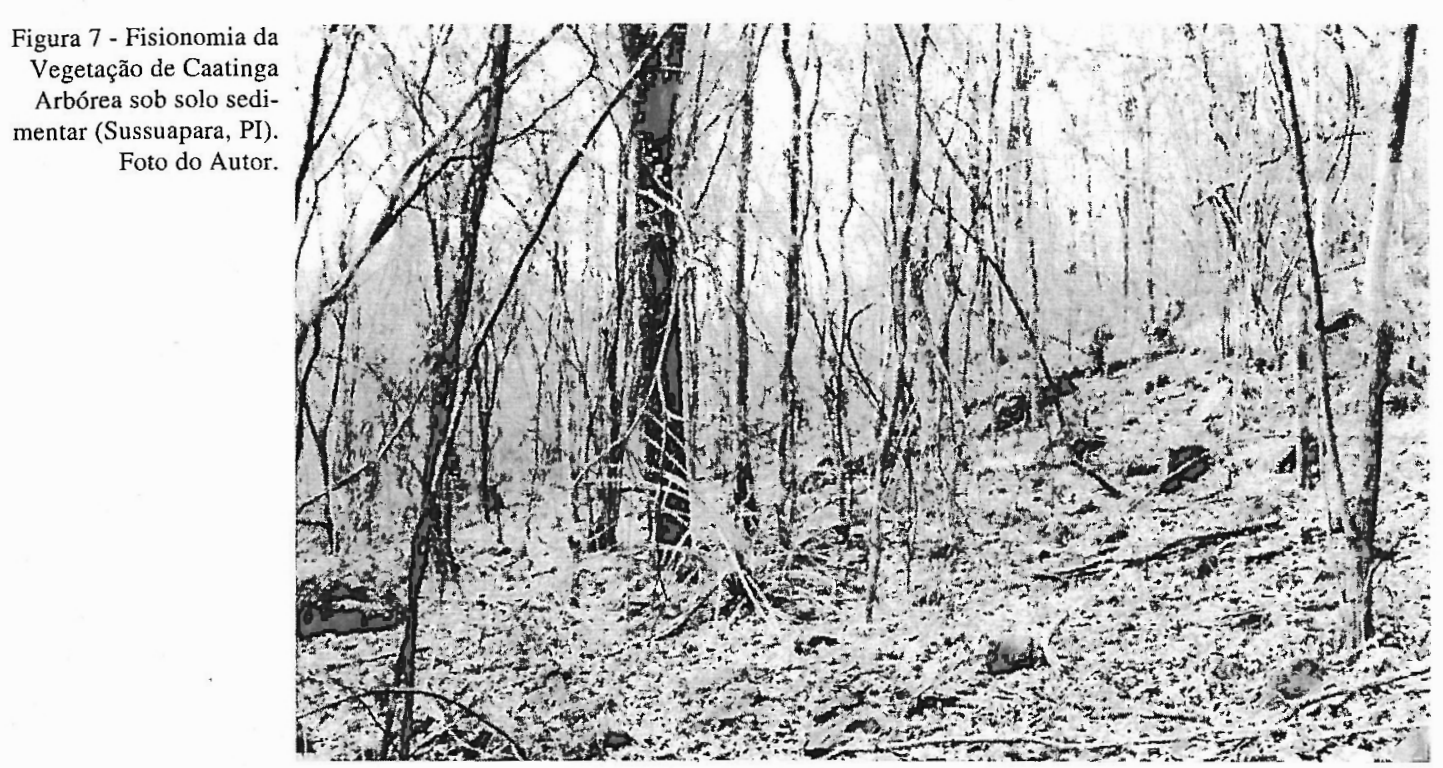

mesmas áreas fossem incluídas em unidades de conservação de uso direto (áreas de uso sustentável), como o déficit é de 7,3\%, áreas de $384.446,47$ a 683.280,0ha; de 381.614,8 a 609.550,0ha e de 119.333,1 a $936.098,71$ ha poderiam ser acrescentadas em.termos de Caatinga, Cerrado e Ecótonos, respectivamente.

Por outro lado, representatividade não está relacionada exclusivamente ao tamanho da área que se deseja conservar, mas também a questões de distribuição delas nos espaços geográfico e ecológico, bem como das suas importâncias biológicas, principalmente. Por enquanto, como o conhecimento ainda é escasso, vale a regra da "precaução". Melhor selecionar a maior e, a partir de dados científicos, redimensionar a menor, do que se fazer o contrário. Se podemos, hoje, remapear o território brasileiro através dos instrumentos poderosos dos "pactos" sociais e políticos autóctones, estimulados pelo espírito do "zoneamento ecológico-econômico", por exemplo, por que não fazê-lo? Do contrário, não vamos sair da inalterabilidade de que o remapeamento é uma prerrogativa das (também nossas) políticas alóctones. Para isto, cada vez mais precisamos aprender a substituir as "parcerias da miséria" pelas "parcerias da abundância".

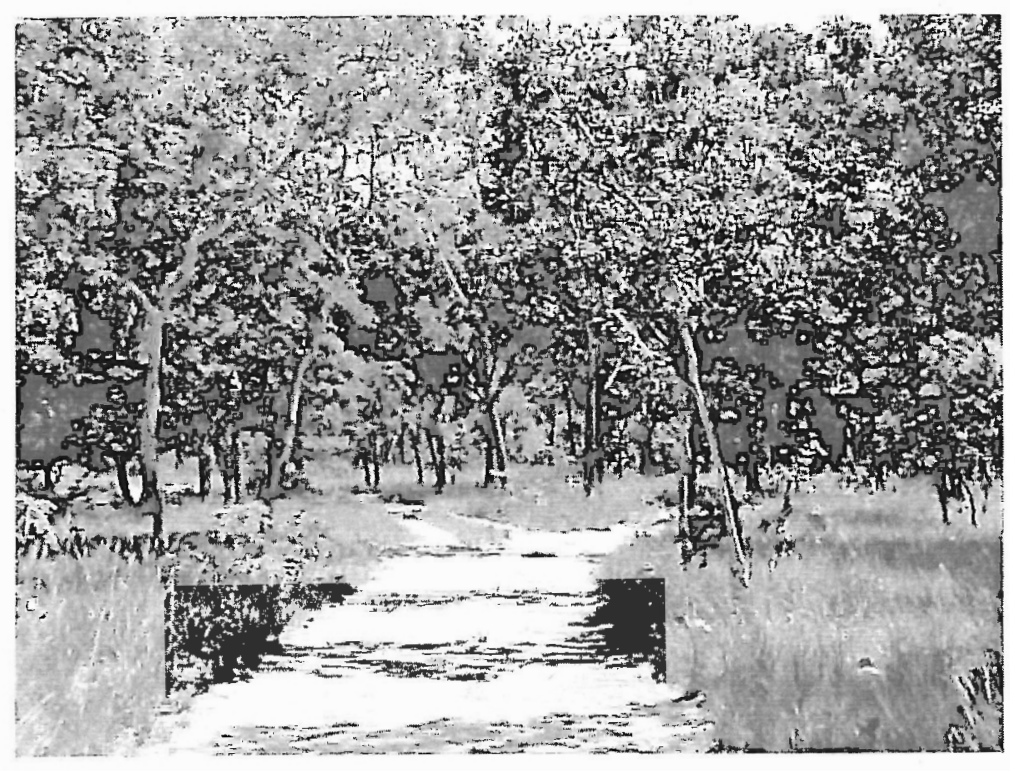

Figura 8 - Fisionomia da Vegetação de Cerrado (Cerradão de Cerrado) (Chapadinha, MA). Foto do Autor. 


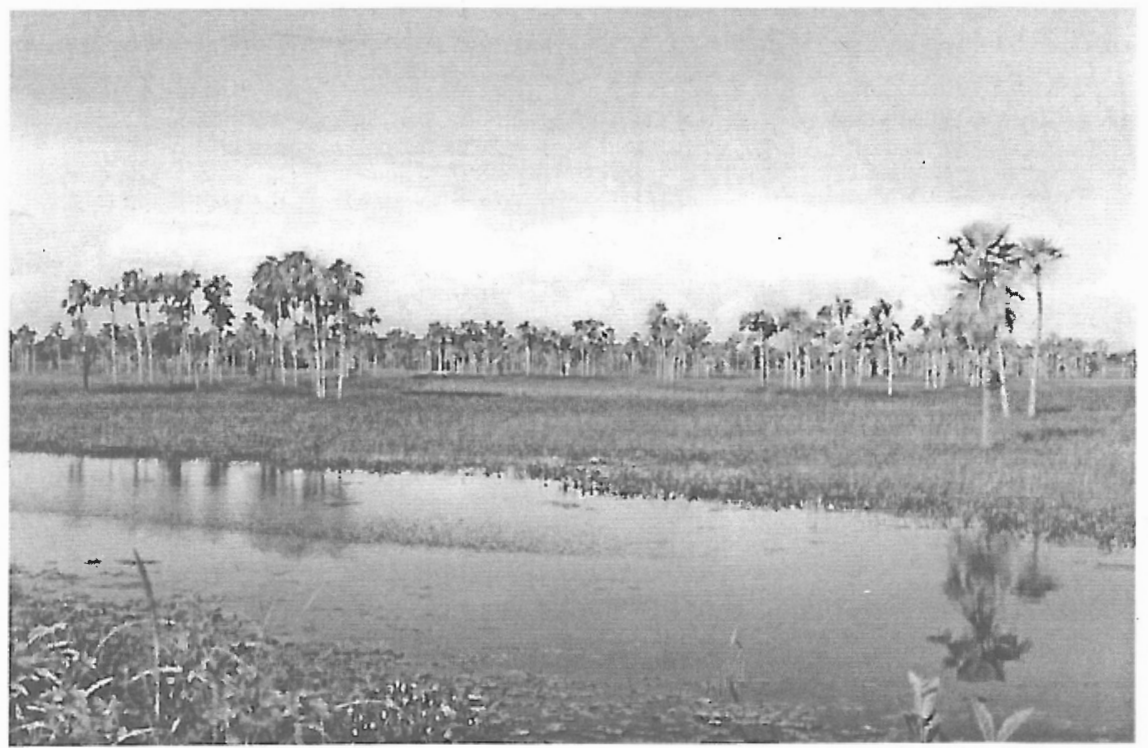

Figura 9 - Fisionomia da Vegetação do Complexo de Campo Maior (Savana de Copernicia). (Campo Maior, PI). Foto do Autor.

\section{Conclusões}

O desenvolvimento cultural, social e econômico da espécie humana, porque depende da biodiversidade como uma das suas mais importantes bases, começa a ser afetado, na medida em que as suas perdas, cada vez mais crescentes, estão associadas à degradação ambiental de solos, águas e atmosfera, à desertificação em regiões áridas, semi-áridas e subúmidas secas e também às rupturas culturais do binômio homem-ambiente associados. A partir daí, um esvaziamento do campo se estabelece, paulatinamente, por conta dos movimentos migratórios (êxodo rural). Estes movimentos começam por ser internos, mas unidirecionais (campo-cidade grande), para depois, dependendo dos vários fatores envolvidos, passarem a extravasar as fronteiras dos Estados, embora atualmente os grandes movimentos Nordeste/Centro-Sul não aconteçam como no passado, porque agora os mesmos estão sendo fortemente desestimulados e até em parte financiados. A promiscuidade em termos da nomeação dos nomes vernaculares (nomes vulgares) das espécies botânicas, associada com o descaso sobre os níveis altos de secundarização, que os "stands" de vegetação primária remanescente se submetem "à frente dos olhos", e os níveis significativos da homogeneização florística que se estabelecem, refletem muito o efeito dessas migrações e daquelas rupturas.

Como o conceito de vulnerabilidade é ainda antropológico a espécie humana não é a única componente 
dabiodiversidade, e certamente nem a mais importante, por conta até das condições sine qua non que a mesma estabelece, as perdas desta biodiversidade ainda não têm visibilidade, a despeito das secas recorrentes do Nordeste do Brasil e da utilização dos recursos naturais da caatinga continuar a acontecer a um nível provavelmente superior ao da sua própria resiliência (resiliência da caatinga comparada com a resiliência dos outros grandes ecossistemas), das queimadas (incêndios florestais) e da desertificação estarem cada vez mais e cada vez mais intensamente se estendendo e determinando o empobrecimento biológico (erosão de genes, de espécies e de ecossistemas) no nosso cotidiano.

A partir dos dados disponíveis sobre as perdas da biodiversidade serem esparsos, muito pouco monitorados, muito pouco financiados para efeitos de prospecção, bem como das defasagens enormes em termos de representatividade (tamanho e qualidade) das unidades de conservação brasileiras, a produção de mapas temáticos georreferenciados, cujos temas se referem a áreas prioritárias para a conservação da biodiversidade, a reservas da biosfera e a ecorregiões, por exemplo, lança para o futuro, deveras próximo, a formulação e execução de políticas públicas a partir da utilização da "vontade política" a bem de todas as humanidades.

A despeito dos riscos naturais e antrópicos, a manutenção inexorável dos serviços da natureza e a repartição dos benefícios da biodiversidade são atualmente condições precípuas para odesenvolvimento sustentável, que seja socialmente mais justo, ecologicamente mais prudente e economicamente mais eficiente.

\section{Agradecimentos}

Os dados brutos sobre desmatamento no estado do Piauí foram fornecidos por Maria da Conceição Sousa Sobrinha, Alcione Riccely Alves da Silva e Maria Socorro Bezerra Lima, técnicas do IBAMA/ PI. Sobre queimadas, os dados foram fornecidos por 'José Ivan dos Santos Cruz (IBAMA/PI) e João Roberto dos Santos (INPE). Sobre unidades de conservação, por sua vez, os dados básicos foram fornecidos por Carlos Antônio Moura Fé (IBAMA/PI). Deocleciano Guedes Ferreira e Eugênia Vitória e Sousa de Medeiros, Gerente Executivo (naquela ocasião) e Gerente Executiva Substituta da Gerência Executiva do IBAMA no Estado do Piauí, autorizaram a cessão dos dados solicitados ao nível do IBAMA/PI. A todos eles, nossos sinceros agradecimentos, porque sem o apoio que nos emprestaram, não teríamos representado tão bem o Piauí durante o IX Encontro sobre Riscos Naturais. Por fim, ao Prof. Dr. Luiz Botelho Albuquer- que, pela leitura do texto e pelas observações pertinentes ao idioma lusitano, nossos agradecimentos.

\section{Referências Bibliográficas}

AB'SÁBER, A.N. (1977) - Problemática da desertificação e da savanização no Brasil intertropical. São Paulo, USP/GG. p.1-19.

ANDRADE-LIMA, D. (1981) - "The caatingas doninium". Revta. brasil. Bot. 4, 149-153.

BAUMER, M. (1987) - Role possible de la agroforesterie dans la lutte contre la desertifation et la degradation de l'environmental. Wageningen, CTA. 260p.

BRITO GUERRA, P.B. (1981) - A civilização da seca. Fortaleza, DNOCS. 324p.

CARVALHO, O. (1988) - A economia politica do Nordeste (seca, irrigação e desenvolvimento). Rio de Janeiro, Campus. 505p.

CASTRO, A.A.J.F. (1994) - Comparação florístico-geográfica (Brasil) e fitossociológica (Piaui-São Paulo) de amostras de cerrado. PhD. Thesis. Campinas, UNICAMP.

CASTRO, A.A.J.F.(2003) - "Survey of the vegetation in the state of Piauí". In: GAISER, T., KROL, M., FRISCHKORN, H., ARAUUJO, J.C. (eds.). Global change and regional impacts: water availability of ecosystems and society in the semiarid northeast of Brazil. Berlin, Springer, p.117-123.

CASTRO, A.A.J.F., PRINTZ, A., MENDES, M.R.A., SOARES, F.A.R., OLIVEIRA, J.O.S., ALBINO, R.S., LANGE, F.-M., FARIAS, R.R.S. (2003) - Cerrado and caatinga in the Picos area. In: GAISER, T., KROL, M.. FRISCHKORN, H., ARAÚJO, J.C. (eds.) - Global change and regional inpacts: water availability of ecosystems and society in the semiarid northeast of Brazil. Berlin, Springer. p.323-333.

COIMBRA-FILHO, A.F., CÂMARA, I.G. (1996) - Os limites originais do bioma mata atlantica na região Nordeste do Brasil. Rio de Janeiro, FBCN.

CONTI, J.B. (2002) - "Riscos naturais na região tropical brasileira". Territorium, Coimbra, MinervaCoimbra, 9, 117-222.

DIAS, B.F.S. (1994)--"Conservação da natureza no cerradobrasileiro". In: PINTO, M.N. (org.). Cerrado: caracterização, ocupação e perspectivas. 2.ed. Brasília, EUnB/SEMATEC. p.583-640.

DOUROJEANNI, M.J., PÁDUA, M.T.J. (2001)-Biodiversidade: a hora decisiva. Curitiba, EUFPR/FBPN, 2001. 307p. (Pesquisa, 56).

GOMES, J.M.A., CARVALHO, F.P.A. (2002)-Qualidade de vida no semi-árido piauiense. Teresina, TROPEN/UFPI. 98p. (Relatório de Projeto de Pesquisa). (Mimeografado).

IBGE. Instituto Brasileiro de Geografia e Estatística (1975) - Censo agropecuário. Rio de Janeiro, IBGE.

IBGE. Instituto Brasileiro de Geografia e Estatística (1985) - Censc agropecuário. Rio de Janeiro. IBGE. 
IBGE. Instituto Brasileiro de Geografia e Estatística (1991) - Censo demográfico. Rio de Janeiro, IBGE.

IBGE. Instituto Brasileiro de Geografia e Estatística (1993) - Base de informações municipais. Rio de Janeiro, IBGE.

IBGE. Instituto Brasileiro de Geografia e Estatística (1998) - Censo agropecuário; 1995-1996; Piauí. n.8. Rio de Janeiro, 1998. 205p. (Estudos \& Pesquisas, Informação Geográfica, 2).

IBGE. Instituto Brasileiro de Geografia e Estatística. (2002) Indicadores de desenvolvimento sustentável; Brasil 2002. Rio de Janeiro, 2002. 195p. (Estudos \& Pesquisas, Informação geográfica, 2).

MARCHIORI, J.N.C. (1992) - "Areais no Sudeste do Rio Grande do Sul: elementos para uma história natural". Ciência e Ambiente, 3: $65-89$.

MENDES, M.R.A., CASTRO, A.A.J.F. (2003) - Florística e fitossociologia de um fragmento de caatinga arbórea, São José do Piauí, Piauí. MSc. Thesis, Recife. UFPE/TROPEN. 111 p. (No prelo).

MILLER, K.R. (1997) - Em busca de um novo equilibrio; diretrizes para aumentar as oportunidades de conservação da biodiversidade por meio do manejo biorregional. Brasília, IBAMA/GTZ. 94p.

MMA. Ministério do Meio Ambiente. (2002)-Sistema Nacional de Unidades de Conservação da Natureza. Brasília, MMA.

MMA. Ministério do Meio Ambiente. Secretaria de Políticas para o Desenvolvimento Sustentável. (2002) - Zoneamento ecologico-econômico do baixo rio Parnaíba: subsídios técnicos; relatório final. Brasília, MMA/SDS. 92p.

PÁDUA, M.T.J., DIAS, B.F.S. (1998) - Representatividade de unidades de conservação do cerrado e do pantanal matogrossense. Brasília, MMA. (Mimeografado).

PEREIRA, P.G.P., CAVALCANTI, R.B., NOVAES, W. (1998) Workshop para discussãoe elaboração do plano de ação para os ecossistemas do cerrado; documentos de apoio. Brasília, MMA/SIP/DEMAI/PNMA. 28p.

REBELO, F. (2001) - Riscos naturais e acção antrópica. Coimbra, Imprensa da Universidade de Coimbra. 274p.

REIS, J.G. (1988) - Desertificação no Nordeste. Recife, SUDENE. $40 \mathrm{p}$.

RIVAS, M.P.(coord.).(1996)-Macrozoneamento geoambiental da bacia hidrográfica do rio Parnaíba. Rio de Janeiro, IBGE. (Série Estudos e Pesquisas em Geociências, 4).

RODRIGUES, S.M.C.B. (1998) - Florística e fitossociologia de uma área de cerrado em processo de desertificação no município de Gilbués - PI. MSc. Thesis. Recife, UFPE. 138p.
RODRIGUES, V., MATALLO JÚNIOR, H., SALES, M.C.L., GALVÃO, A.L.C., GORGÔNIO, A.S. (1995) - "Avaliação do quadro da desertificação no Nordeste do Brasil; diagnóstico e perspectiva". In: GOMES, G.M., SOUZA, H.R., MAGALHÃES, A.R. (eds.). Desenvolvimento sustentável no Nordeste. Brasília, IPEA.

SALES, M.C.L. (1998) - Estudo da degradação ambiental em Gilbués-PI: reavaliando o "núcleo de desertificação". MSc. Thesis, São Paulo. USP/ FFLCH/UFPI/TROPEN.

SALES, M.C.L. (2002) - "Evolução dos estudos de desertificação no Nordeste brasileiro". GEOUSP Espaço e Tempo 11, 115-126.

SAMPAIO, E.V.S.B., SAMPAIO, Y. (2002) - Desertificação: conceitos, causas, conseqüencias e mensuração. Recife, EDUFPE.

SOUZA, M.J.N. de, MARTINS, M.L.R., SOARES, Z.M.L., FREITAS FILHO, M.R. de, ALMEIDA, M.A.G. de, PINHEIRO, F.S. de, SAMPAIO, M.A.B., CARVALHO, G.M.B. de S., SOARES, A.M.L., GOMES, E.C.B., SILVA, R.A. da S. (1994)-Redimensionamento da região semi-árida do Nordeste do Brasil. In: CONFERÊNCIA NACIONAL E SEMINÁRIO LATINO-AMERICANO DA DESERTIFICAÇÃO. Fortaleza, 1994. Brasília, Fundação Esquel do Brasil/PNUD/ BNB. 25p.

TABARELLI, M., SILVA, J.M.C., SANTOS, A.M.M., SANTOS, A.V. (2000)-Análise de representatividade das unidades de conservação de uso direto e indireto na caatinga; documento preliminar. Recife, MMA. (Mimeografado).

TCA. Tratado de Cooperacion Amazonica. (1992) - Amazonia sin mitos. Quito, BID/PNUD/TCA. 111p.

THOMAS, A.L. (1994) - "Ciencias sociales y desastres naturales en America Latina: un encuentro inconcluso". In: Questões teorico-metodológicas para o estudo e pesquisa na área de calamidades; série leituras. Campina Grande, vol.1, n.1, 18p.

THOMAS, A.L. (comp.). (1994)-Al norte del Río Grande; ciencias sociales, desastres: una perspectiva norteamericana. Santafé de Bogotá, LA RED/Tercer Mundo Editores. 154p.

VASCONCELOS SOBRINHO, J. (1978) - Identificação de processos de desertificação no poligono das secas do Nordeste brasileiro. Recife, SUDENE.

VELLOSO, A.L., SAMPAIO, E.V.S., PAREYN, F.G.C. (eds.). (2002) - Ecorregiões; propostas para o bioma caatinga; resultados do seminário de planejamento ecorregional da caatinga. Recife, TNC/APNE. 75p.

WWF. Fundo Mundial para a Natureza. (2000) - Ecorregiōes do Brasil. Brasília, WWF. 